\title{
INTERLEUKIN 21 AS A DIAGNOSTIC MARKER OF RHEUMATOID ARTHRITIS.
}

1. MBBS, M Phil

Assistant Professor

Department of Physiology

Gujranwala Medical College,

Gujranwala.

2. MBBS, M Phil

Assistant Professor

Department of Physiology

Abbotabad International Medical and Dental College.

3. MBBS, MS

Consultant Orthopedic Surgeon

Department of Orthopedics

THQ Sambrial.

Correspondence Address:

Dr. Khadija Kiran

MBBS, M Phil

Bhatti Manzil Opposite Sahi Market

Main DC Road, Gujranwala.

drkhadijakran@gmail.com

Article received on:

05/12/2018

Accepted for publication:

14/04/2019

Received after proof reading:

31/07/2019

\section{INTRODUCTION}

Among chronic diseases of autoimmune system Rheumatoid Arthritis is fatal one chractarised as synovial inflammation, synovial tissue hyperplasia, synovial bone and cartilage destruction. ${ }^{1}$ Fibroblasts like synoviocytes play an important role in its development like other contributing factors or events. ${ }^{2}$ Fibroblasts like synoviocytes (FLS) stimulate the affected synovium to migrate towards healthy and fresh synovium in arthritis patients. This shift of synovium is responsible for destruction of synovium and physiology. FLS involve the extracellular matrix and responsible for release of Metalloproteinases which are responsible for the destruction of cartilage bone and joints. ${ }^{3}$

In the start and progression of rheumatoid arthritis cytokines play an important role. ${ }^{4}$ The activation of synoviocytes and development of rheumatoid arthritis involves many pro inflammatory cytokines like interleukin six and tumour necrosis factor alpha. ${ }^{5}$ In patients of the rheumatoid arthritis development and progression of disease can be prevented by regulating the pro inflammatory cytokines. ${ }^{6}$ Among the family of IL-2 cytokines IL21 is an important member which binds with IL-21 receptors and form IL-21 $\mathrm{R}$ which is a heterodimer. Expression of IL-21 initially is found by $\mathrm{CD} 4^{+} \mathrm{T}$ cells and natural killer of T cells. ${ }^{7}$

In the rheumatoid synovium tissues RA-FLS plays role in expression of IL-21 R. In advance Condition of rheumatoid arthritis patients increase level of IL-21 was found in plasma which is a diagnostic marker of enhanced disease activity. 8,9 Progression of arthritis and inflammatory cytokines production can be reduced and attenuated by inhibiting the IL-21 with fusion of FC proteins. In streptococcal cell wall arthritis IL-21 $\mathrm{R}$ deficiency protects the inflammatory joints destruction in severe cases. ${ }^{10}$

In a study conducted by Montleone $\mathrm{G}$ et al ${ }^{11}$ reported that IL-21 enhances the MMPs expression 
in fibroblasts initiation. Degradation of ECM and basement membranes are also due to the role of MMPs which are dangerous for invasion and migration of severe types of cells. Because of lack of literature available on this topic and role of IL-21 on RA-FLS invasion and migration further studies needed to investigate and prompted the potential effect of IL-21. ${ }^{12,13}$ In our study we investigate the diagnostic role of IL-21 in diagnosis of rheumatoid arthritis and to evaluate the diagnostic accuracy of IL-21 as a diagnostic marker.

\section{METHODOLOGY}

The study was started and completed in the Department of Physiology and Orthopedic Gujranwala Medical College, Gujranwala, from October 2017 to October 2018 in one year duration. Study was started after the ethical approval from ethical board of institution and written informed consents from the patients. Non probability consecutive sampling technique was used. Patients of age limit 30 to 60 years both genders and who were suspected for rheumatoid arthritis on history and clinical examination were involved in the study. Patients having any musculoskeletal disease, diabetes, congenital anomales and comorbid disease were excluded from the study.

Patient's sample of synovial tissues were obtained mechanically and send to the laboratories where it was washed in steroid cold buffered phosphate salines and digested with disphase II 150mg/ $\mathrm{ml}$ at 37 degree centigrade for four hours and egitated gently. After that cell culture was done in Dulbecco,s modified the eagles medium. Fetal bovin serum (10\%), 100mg/ml streptomycin and penicillin G $100 \mathrm{U} / \mathrm{ml}$ and incubated in $5 \% \mathrm{cow}$ enriched environment at 37 degree centigrade was used for supplimentation. Passages 4/7 used for cells culture and flow cytometric analysis. Reverse transcription polymerase chain reaction was used for extraction of RNA and enzyme linked immunosorbent assay (Elisa) was used to measure the cytokines concentration after the store of cell culture at 80 degree centigrade. Patient's blood samples were taken with all aseptic measures and stored in gel vial and send to the laboratories for RA factor.
Computer software SPSS version 23 was used for composition and analysis of the data. Numerical variables were calculated and presented as mean and standard deviation and qualitative variables were calculated and presented as frequency percentages. $2 \times 2$ contingency table was drawn for for positive and negative predictive values. Sensitivies, specificities and diagnostic accuracy was calculated.

\section{RESULTS}

One hundred and fifty patients were included in this study. It was observed that 131 patients with RA factor as well as on IL 21, known as true positive. Five patients with IL-21 are present on IL-21 but absent on RA factor, known as false positive. 9 patients had RA factor but absent on IL 21, labeled as false negative. Five patients had no on RA factor and also absent on IL 21, labeled as true negative. The difference was statistically significant $(p=0.000)$. (Table-l).

Therefore, the estimated sensitivity was $93.6 \%$. The estimated specificity was $50 \%$. Positive predictive value was $96.3 \%$ and negative predictive value was $35.7 \%$. The overall accuracy was $90.6 \%$ for diagnosing rheumatoid arthritis. (Table-II)

\begin{tabular}{|c|c|c|c|c|}
\hline \multirow{2}{*}{ IL 21} & \multicolumn{2}{|c|}{ RA Factor } & \multirow{2}{*}{ Total } & \multirow{2}{*}{ P-Value } \\
\hline & Yes & No & & \\
\hline Yes & $\begin{array}{c}\text { True } \\
\text { positive } \\
131\end{array}$ & $\begin{array}{c}\text { False } \\
\text { positive } \\
5\end{array}$ & 136 & \multirow{3}{*}{0.000} \\
\hline No & $\begin{array}{c}\text { False } \\
\text { Negative } \\
9\end{array}$ & $\begin{array}{c}\text { True } \\
\text { negative } \\
5\end{array}$ & 14 & \\
\hline Total & 140 & 10 & 150 & \\
\hline \multicolumn{5}{|c|}{$\begin{array}{l}\text { Table-I. Comparison of RA factor and IL } 21 \text { the } \\
\text { diagnosis of rheumatoid }(n=150)\end{array}$} \\
\hline \multicolumn{3}{|c|}{ Diagnostic Measures } & \multicolumn{2}{|c|}{ Value } \\
\hline \multicolumn{3}{|c|}{ Sensitivity } & \multicolumn{2}{|c|}{$93.6 \%$} \\
\hline \multicolumn{3}{|c|}{ Specificity } & \multicolumn{2}{|c|}{$50 \%$} \\
\hline \multicolumn{3}{|c|}{ Positive Predictive Value (PPV) } & \multicolumn{2}{|c|}{$96.3 \%$} \\
\hline \multicolumn{3}{|c|}{ Negative Predictive Value (PPV) } & \multicolumn{2}{|c|}{$35.7 \%$} \\
\hline \multicolumn{3}{|c|}{ Accuracy } & \multicolumn{2}{|c|}{$90.6 \%$} \\
\hline
\end{tabular}

\section{DISCUSSION}

In our study we observed diagnostic role of IL- 
21 in patients of rheumatoid arthritism in a study conducted by Xing $\mathrm{R}$ et $\mathrm{al}^{13}$ reported involvement of IL-21 in invasion and migration of fibroblasts like synoviocytes in samples of the rheumatoid arthritis patients which shows that IL-21 can be used as a diagnostic marker of rheumatoid arthritis. Huber LC et $\mathrm{al}^{14}$ conducted a study on synovial fibroblasts and its key role in rheumatoid arthritis and reported that RA FLS have capability of invasion and migration into the bones and cartilage during progression of RA.

Liu $\mathrm{R}$ et $\mathrm{al}^{15}$ conducted a study in regulatory effects of IL-21 on helper like cells in rheumatoid arthritis and concluded that IL-21 may be involved in rheumatoid arthritis pathogenesis so it can be used as a diagnostic marker of rheumatoid arthritis he also concluded that by antagonising the IL-21 treatment cause of rheumatoid arthritis can be achieved. This study goes in favour of our study. Another study by Lebre MC et $\mathrm{al}^{16}$ conducted on this topic in 2017 and reported involvement of $\mathrm{CD}^{+} \mathrm{IL}-21^{+} \mathrm{TNF}^{+} \mathrm{T}$ cells in destruction of synovium. Result of his study also indicates the role of IL-21 as a diagnostic marker of rheumatoid arthritis.

Xiaoyin Niu et al ${ }^{17}$ conducted a study in 2014 on clinical biomarkers of rheumatoid arthritis and reported that along with multiple organic factors IL-21 is a contributing factor which induce the MMP3 in rheumatoid arthritis and express presence in synovial joints and fluid. By indicating the presence of IL-21 in synovium rheumatoid arthritis can be treated earlier. Magyari $L$ et $a^{18}$ conducted a study on involvement of interleukins in rheumatoid arthritis and reported identification of disease-associated interleukin to disease onset in order to identify the pathways important for RA pathogenesis.

In 2017 Dinesh $\mathrm{P}$ et al ${ }^{19}$ and reported role of IL-21 in rheumatoid arthritis pathogenesis, he also reported function of IL-21 in immune cells that promotes synovial destruction of cartilage and bone. Its involvement was also described in important signaling pathways. Cañete JD et $\mathrm{al}^{20}$ conducted a study on role of cytokines and other soluble factors as diagnostic biomarker and shows that its presence can be confirmed by ELISA and gene expression. Cytokines were separated from joint sample of chronic disease patients of rheumatoid arthritis.

\section{CONCLUSION}

Results of our study reveal that IL-21 induces MMP3 in rheumatoid arthritis patients; identification of IL-21 from synovium of patients indicates the presence of rheumatoid arthritis. We observed $90.6 \%$ diagnostic accuracy of IL-21 for rheumatoid patients taking RA factor as gold standard of diagnostic tool.

Copyright $\odot 14$ Apr, 2019.

\section{REFERENCES}

1. Roeleveld DM, van Nieuwenhuijze AEM, van den Berg WB, Koenders MI. The Th17 pathway as a therapeutic target in rheumatoid arthritis and other autoimmune and inflammatory disorders. Bio Drugs. 2013; 27:43952.

2. Piper C, Pesenacker AM, Bending D, Thirugnanabalan $B$, Varsani $H$, Wedderburn LR, et al. T cell expression of granulocyte-macrophage colony-stimulating factor in juvenile arthritis is contingent upon Th17 plasticity. Arthritis Rheumatol. 2014; 66:1955-60.

3. Van Nieuwenhuijze AE, Coghill E, Gray D, Prato S, Metcalf $D$, Alexander WS, et al. Transgenic expression of GMCSF in T cells causes disseminated histiocytosis. Am J Pathol. 2014; 184:184-99.

4. Van Nieuwenhuijze A, Koenders M, Roeleveld D, Sleeman MA, van den Berg W, Wicks IP. GM-CSF as a therapeutic target in inflammatory diseases. Mol Immunol. 2013; 56:675-82.

5. Klein K, Kabala PA, Grabiec AM, et al The bromodomain protein inhibitor I-BET151 suppresses expression of inflammatory genes and matrix degrading enzymes in rheumatoid arthritis synovial fibroblasts. Annals of the Rheumatic Diseases 2016; 75:422-29.

6. Gharibi T, Majidi J, Kazemi T, Dehghanzadeh $R$, Motallebnezhad M, Babaloo Z. Biological effects of IL-21 on different immune cells and its role in autoimmune diseases. Immunobiology. 2016; 221(2):357-67.

7. Audo R, Deckert V, Daien $\mathrm{Cl}$. Phospho Lipid transfer protein (PLTP) exerts a direct pro-inflammatory effect on rheumatoid arthritis (RA) fibroblasts-likesynoviocytes (FLS) independently of its lipid transfer activity. PLoS One. 2018; 13(3):e0193815. 
8. Brehm A, Geraghty P, Campos M, Garcia-Arcos I, Dabo AJ, Gaffney A, et al. Cathepsin G degradation of phospholipid transfer protein (PLTP) augments pulmonary inflammation. FASEB J. 2014; 28(5):231831.

9. Yu Y, Cui Y, Zhao Y, Liu S, Song G, Jiao P, et al. The binding capability of plasma phospholipid transfer protein, but not HDL pool size, is critical to repress LPS induced inflammation. Sci Rep. 2016; 6:20845.

10. Aletaha D, Neogi T, Silman AJ, Funovits J, Felson DT, Bingham CO 3rd, et al. 2010 rheumatoid arthritis classification criteria: An American College of Rheumatology/European League Against Rheumatism collaborative initiative. Ann Rheum Dis. 2010; 69(9):1580-8.

11. Monteleone G, Caruso R, Fina D. Control of matrix metal- loproteinase production in human intestinal fibroblasts by inter- leukin 21. Gut 2006; 55:1774-80.

12. Deckert V, Lemaire S, Ripoll PJ, de Barros JP, Labbe $\mathrm{J}$, Borgne CC, et al. Recombinant human plasma phospholipid transfer protein (PLTP) to prevent bacterial growth and to treat sepsis. Sci Rep. 2017; 7(1):3053.

13. Elshabrawy HA, Chen Z, Volin MV, Ravella S, Virupannavar S, Shahrara $S$. The pathogenic role of angiogenesis in rheumatoid arthritis. Angiogenesis. $2015 ; 18(4): 433-48$.

14. Xing $R$, Jin $Y$, Sun $L$. Interleukin-21 induces migration and invasion of fibroblast-like synoviocytes from patients with rheumatoid arthritis. Clin Exp Immunol. 2016; 184(2):147-58.
15. Huber LC, Distler O, Tarner I, Gay RE, Gay S, Pap T. Synovial fibroblasts: key players in rheumatoid arthritis. Rheumatology (Oxf) 2006; 45:669-75.

16. Liu $R$, Wu $Q$, Su $D$, et al. A regulatory effect of IL-21 on $T$ follicular helper-like cell and $B$ cell in rheumatoid arthritis. Arthritis Res Ther. 2012; 14(6):R255.

17. Lebre MC, Vieira PL, Tang MW, Aarrass S, Helder B, Newsom-Davis T et al. Synovial IL-21/TNF-producing CD4 + T cells induce joint destruction in rheumatoid arthritis by inducing matrix metalloproteinase production by fibroblast-like synoviocytes. J Leukoc Biol. 2017; $101(3): 775-83$.

18. Niu X, Chen G. Clinical biomarkers and pathogenicrelated cytokines in rheumatoid arthritis. $J$ Immunol Res. 2014; 2014:698192.

19. Magyari L, Varszegi D, Kovesdi E, et al. Interleukins and interleukin receptors in rheumatoid arthritis: Research, diagnostics and clinical implications. World J Orthop. 2014; 5(4):516-36.

20. Dinesh P, Rasool M. Multifaceted role of IL $\square 21$ in rheumatoid arthritis: Current understanding and future perspectives. J Cell Physiol. 2018; 233(5):391828.

21. Cañete, J. Llena, A. Collado et al., "Comparative cytokine gene expression in synovial tissue of early Rheumatoid Arthritis and seronegative spondyloarthropathies," British Journal of Rheumatology 1997; 36(1):38-42.

\section{AUTHORSHIP AND CONTRIBUTION DECLARATION}

\begin{tabular}{|c|l|l|l|}
\hline Sr. \# & \multicolumn{1}{|c|}{ Author-s Full Name } & \multicolumn{1}{|c|}{ Contribution to the paper } & Author=s Signature \\
\hline 1 & Khadija Kiran & $\begin{array}{l}\text { Conceived idea, Study design, } \\
\text { Paper writing. }\end{array}$ \\
\hline 2 & Amtul Huda & $\begin{array}{l}\text { Data Collection, Literature } \\
\text { review, Data analysis. } \\
\text { Manuscript writing, Data } \\
\text { analysis, Literature review. }\end{array}$ \\
\hline
\end{tabular}

